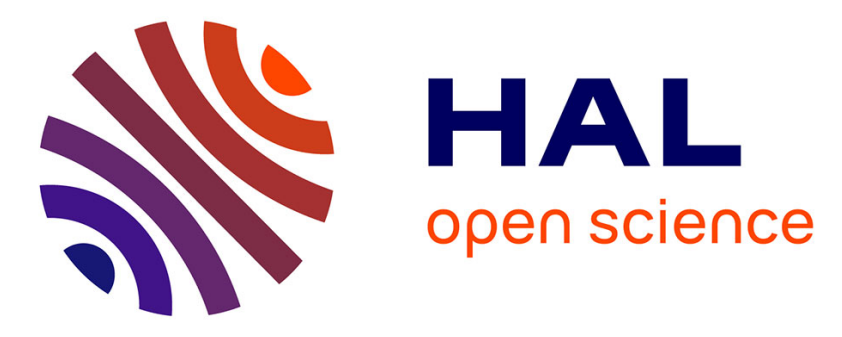

\title{
Relevance of using a compressive preload in the cervical spine: an experimental and numerical simulating investigation
}

Cédric Barrey, Marc-Antoine Rousseau, Sylvain Persohn, Sophie Campana, Gilles Perrin, Wafa Skalli

\section{To cite this version:}

Cédric Barrey, Marc-Antoine Rousseau, Sylvain Persohn, Sophie Campana, Gilles Perrin, et al.. Relevance of using a compressive preload in the cervical spine: an experimental and numerical simulating investigation. European Journal of Orthopaedic Surgery \& Traumatology, 2015, 25, pp.155-165. 10.1007/s00590-015-1625-2 . hal-02611560

\author{
HAL Id: hal-02611560 \\ https://hal.science/hal-02611560
}

Submitted on 18 May 2020

HAL is a multi-disciplinary open access archive for the deposit and dissemination of scientific research documents, whether they are published or not. The documents may come from teaching and research institutions in France or abroad, or from public or private research centers.
L'archive ouverte pluridisciplinaire HAL, est destinée au dépôt et à la diffusion de documents scientifiques de niveau recherche, publiés ou non, émanant des établissements d'enseignement et de recherche français ou étrangers, des laboratoires publics ou privés. 


\title{
Relevance of using a compressive preload in the cervical spine: an experimental and numerical simulating investigation
}

\author{
Cédric Barrey ${ }^{1,2,3} \cdot$ Marc-antoine Rousseau $^{3} \cdot$ Sylvain Persohn $^{3} \cdot$ Sophie Campana ${ }^{3}$. \\ Gilles Perrin $^{1,2} \cdot$ Wafa Skalli ${ }^{3}$
}

\begin{abstract}
Summary of background data Simulating compressive action of muscles, a follower load attends to reproduce a more physiological biomechanical behaviour of the cervical spine. Only few experimental studies reported its influence on kinematics and intradiscal pressure in the cervical spine.

Study design In vitro human cadaveric and numerical simulating evaluation of a compressive preload in the cervical spine.

Objectives To analyse the influence of a compressive follower preload on the biomechanical behaviour of the cervical spine.

Methods The present study was divided into two parts: part 1: in vitro investigation; part 2: numerical simulating analysis. Part 1: Twelve human cadaveric spines from $\mathrm{C} 2$ to $\mathrm{T} 2$ were evaluated intact and after application of a $50-\mathrm{N}$ follower load. All tests were performed under load control by applying pure moments loading of $2 \mathrm{Nm}$ in flexion/ extension (FE), axial rotation (AR) and lateral bending (LB). Three-dimensional displacements were measured using an optoelectronic system, and intradiscal pressures were measured at two levels. Part 2: Using a 3D finite element model, we evaluated the influence of a 50- and $100-\mathrm{N}$ compressive preload on intradiscal loads, facets
\end{abstract}

Cédric Barrey

c.barrey@wanadoo.fr; cedric.barrey@chu-lyon.fr

University Claude Bernard Lyon 1, Lyon, France

2 Department of Spine Surgery, Hôpital P Wertheimer, 59 boulevard Pinel, 69394 Lyon, France

3 Laboratory of Biomechanics, ENSAM, Arts et Metiers ParisTech, 151 boulevard de l'Hôpital, 75640 Paris, France forces and ranges of motion. Different positions of the follower load along the anteroposterior axis $( \pm 5 \mathrm{~mm})$ were also simulated.

Results Part 1: Mean variation of cervical lordosis was $5^{\circ} \pm 3^{\circ}$. The ROM slightly increased in FE, whereas it consistently decreased in AR and LB. Coupled lateral bending during AR was also reduced. Increase in hysteresis was observed on load-displacement curves only for AR and LB. Intradiscal pressures increased, but the aspect of load-pressure curves was altered in AR and LB. Part 2: Using the FE model, only minimal changes in ROM were noted following the simulation of a 50-N compressive load for the three loading conditions. Compared to intact condition, $<10 \%$ variation was observed with regard to the different magnitude and positioning simulated. Intradiscal loads and facets forces were systematically increased by applying compressive preload.

Conclusions Although the follower load represents an attractive option to apply compressive preload during experimental tests, we found that this method could affect the native biomechanical behaviour of spine specimen depending on which movement was considered. Only minimal effects were observed in FE, whereas significant changes in kinematics and intradiscal pressures were observed for AR and LB.

Keywords Biomechanics - Biomechanical testing · Cervical spine $\cdot$ Preload · Spinal implants · Follower load

\section{Introduction}

In vitro investigations of cervical spine implants represent an important preclinical step prior to their implantation in humans [1-4]. However, this in vitro evaluation 
implies to reproduce closely as possible in vivo conditions during experimental tests. Although in vitro investigations permit to analyse the biomechanical behaviour of spinal segments under precise control of applied forces with accurate measurement of intersegmental range of motion [5-7], one limitation is that the effect of the musculature is only partially reproduced [5, 8].

Predominant action of paraspinal muscles is considered to mainly result in axial compressive forces [9-12]. To simulate physiological compressive loads, some authors evaluated different testing protocols by applying compressive preload [9, 11-15]. However, most experimental studies were reported in the lumbar spine [14-17]. Only few experimental studies investigated the effects of a compressive preload in the cervical spine [11, 13, 18]. In addition, Panjabi et al. [11] demonstrated that application of a pure vertical compressive load on the cervical spine resulted in collapse of spinal specimen at very low loads far below physiological loads. Similar findings were reported by Patwardhan et al. [13].

Therefore, Patwardhan proposed a method to apply compressive preload consisting of a follower preload applied along the spinal segment, remaining tangent to the spinal curve and allowing for reduction in bending moments [13]. Using this follower load protocol, these authors reported that the cervical spine specimens could support a $120-\mathrm{N}$ compressive load versus only $20 \mathrm{~N}$ in case of vertical load [12, 13].

Although using follower load to apply compressive load could be an attractive option to simulate physiological muscles action, the way that a follower load may precisely affect spine posture, spine kinematics and loads transfer in the cervical spine has only been partly reported. In addition, Miura et al. [18] reported that compressive preload affected spinal motion differentially depending on which direction was considered. True impact of follower load positioning in relation with the centre of rotation has not been clearly investigated for the cervical spine. For these reasons, no standardisation has been established with regard to the conditions in which compressive preload should be applied and there are still controversies to use systematically axial preload during in vitro cadaveric testing $[2$, 7].

The objective of the present study was then to fully investigate the biomechanical influence of a follower load in the cervical spine in terms of spine posture, spinal kinematics and intradiscal pressure (IDP) using both in vitro human cadaveric and numerical simulating evaluations.

\section{Materials and methods}

\section{Part 1 in vitro tests}

\section{Spinal specimen preparation}

Twelve adult cervical spines were harvested from fresh human cadavers coming from the department of anatomy of the University. Each spinal segment included C2 to T2 vertebrae. There were six male and six female with a mean age at death of $62 \pm 6.4$ years (55-77).

Radiographs were performed to exclude pathologic spines. Once harvested, each spine was immediately conserved in plastic bags at $-20{ }^{\circ} \mathrm{C}$. The day before biomechanical testings, all spines were thawed at $+4{ }^{\circ} \mathrm{C}$ for $12 \mathrm{~h}$. On the day of testing, all soft tissues including paravertebral muscles were removed while preserving spinal ligaments, joint capsules, discs and bony elements.

The cranial vertebra (C2) was fixed in a container using a low-fusion point alloy (MCP 70, MCP Metalspecialities Inc, Fairfield, CT), whereas the caudal vertebra (T2) was firmly mounted in a specific device designed with metallic rods and screws.

\section{Compressive preload}

A 50-N compressive preload was applied symmetrically each side by two waxed and flexible cables fixed at the top container and passing through brass-drilled-head screws that were inserted between the anterior and posterior ridges of the transverse processes from $\mathrm{C} 3$ to $\mathrm{C} 7$ (Fig. 1). These guiding screws were approximately positioned at the posterior third of the vertebral body, close to the theoretical location of the mean axis of rotation in flexion-extension [19-21].

\section{Biomechanical tests protocol}

Tests were performed at room temperature; in order to avoid tissue dehydration, specimens were kept moistened with physiological saline serum spray during the tests.

Loads were applied to the upper vertebra (C2), which was allowed to move unconstrained in all degrees of freedom. Pure moments loading was successively applied in flexion/extension, lateral bending and axial rotation to a 2-Nm maximum moment loading with $0.2-\mathrm{Nm}$ steps. Flexion and extension were completed in the same sequence (loading-unloading complete cycle); the same was performed for left and right lateral bending, and for left and right torsion. Three loading cycles were applied for preconditioning the specimen. 

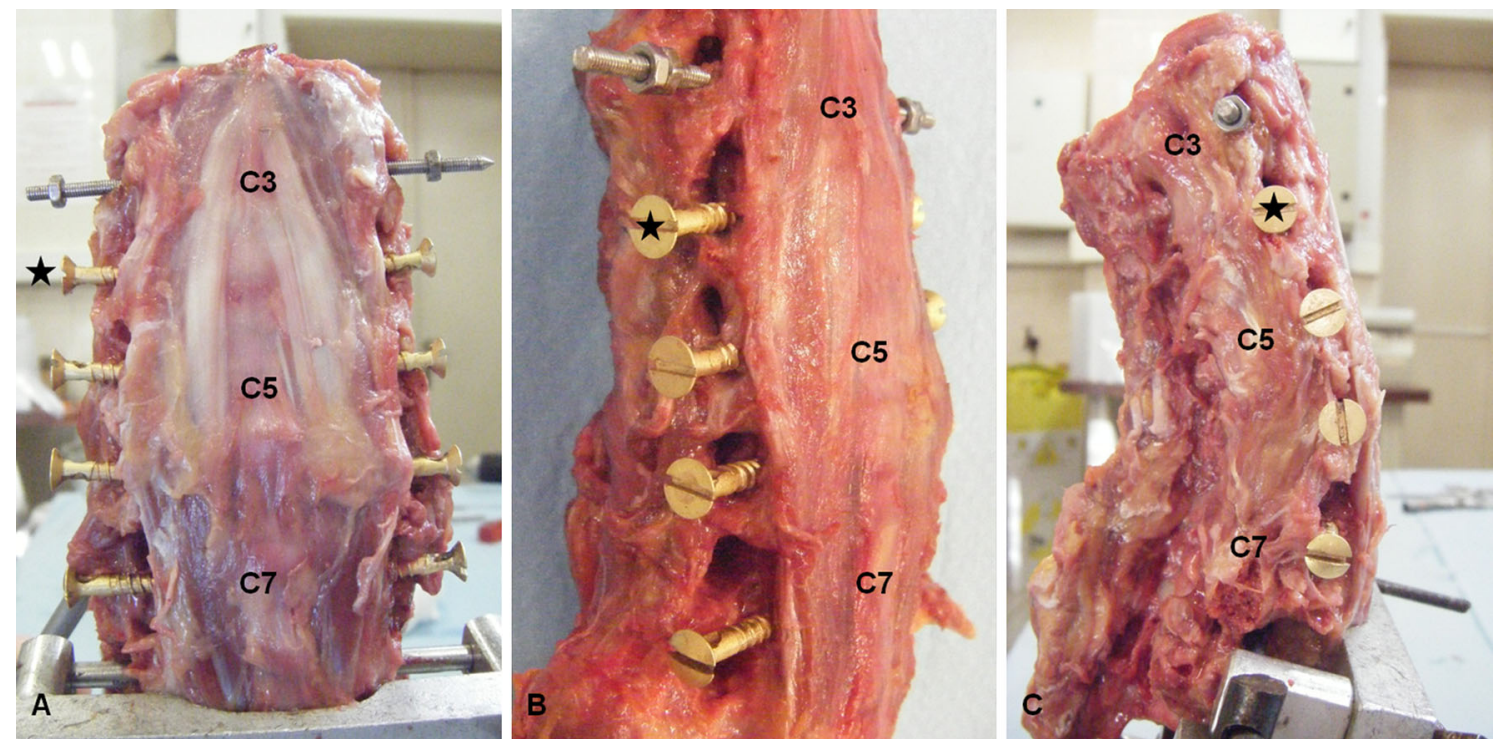

Fig. 1 AP (a), oblique (b) and lateral (c) view of cervical spine specimen after insertion of guiding screws (black star) between anterior and posterior ridges of the transverse process

Each spinal specimen was evaluated sequentially in two conditions: intact and loaded after application of the compressive load.

\section{Displacements measurement}

Biomechanical tests were performed under load control using a three-dimensional optoelectronic measurement system (POLARIS ${ }^{\mathrm{TM}}$ VICRA system, Northern Digital Inc, Waterloo, ON) connected to an acquisition and data processing system. All measurements were performed during the third cycle for each load case reducing the influence of the viscoelastic behaviour of spinal specimens. Angular and linear displacements were measured using reflective markers rigidly fixed on each vertebra from C3 to C7.

To determine the displacements of a vertebra with regard to the lower adjacent one, the anatomical frame of each vertebra and the local frame of its associated reflective markers were determined from $3 \mathrm{D}$ reconstructions that were obtained from $\operatorname{EOS}^{\mathrm{TM}}$ biplanar X-ray system [22, 23], (Fig. 2). Accuracy in linear and angular measurements was previously calculated to $0.5 \mathrm{~mm}$ and $0.5^{\circ}$, respectively.

Typical load-displacement curves were obtained for each different testing condition.

\section{Intradiscal pressure measurement}

Special pressure sensors (EPL-B02-100P; Entran, Fairfield, $\mathrm{NJ})$ were placed into the $\mathrm{C} 3-\mathrm{C} 4$ and $\mathrm{C} 4-\mathrm{C} 5$ intervertebral discs allowing measurement of intradiscal pressure at these levels during experimental tests. They were inserted so that the pressure sensitive area was located at the anterior third of the intervertebral space in the AP plane, at the midheight of the disc and aligned with the midline in the frontal plane. Load sensors position was checked on frontal $\mathrm{AP}$ and lateral radiographs acquired with the stereoradiographic $\mathrm{EOS}^{\mathrm{TM}} \mathrm{X}$-ray system (Fig. 2).

\section{Statistical analysis}

Statistical comparison of spine posture, ROM, NZ and maximal IDP between intact and loaded spines was carried out using paired Wilcoxon test. All $p$ values were considered statistically significant for a $p$ value $<0.05$.

\section{Part 2 finite element modelling}

\section{Construct of FE Model}

A nonlinear three-dimensional FE model of the lower cervical spine was generated in our institution and recently published [24-26]. It consists of a parametric and subjectspecific model, in which mesh was based on hexahedral elements and built from 3D reconstructions using $\operatorname{EOS}^{\mathrm{TM}}$ biplanar imaging system. It is composed of cervical vertebra from $\mathrm{C} 3$ to $\mathrm{C} 7$ and soft tissues including intervertebral discs, endplates, facets cartilage and the main ligament structures (Fig. 3).

All mechanical properties of materials have already been described in detail in the literature [24]. Cortical and cancellous bones have been differentiated, and tensiononly springs elements have been used to model peripheral annulus and ligament structures. Contact interfaces have 
Fig. 2 Prior to biomechanical tests, precise location of reflective markers (fixed on each vertebra from $\mathrm{C} 3$ to $\mathrm{C} 7$ to allow for measurement of $3 \mathrm{D}$ displacements), guiding screws and intradiscal load sensors was determined using AP (a) and Lateral (b) views of cervical spine specimen
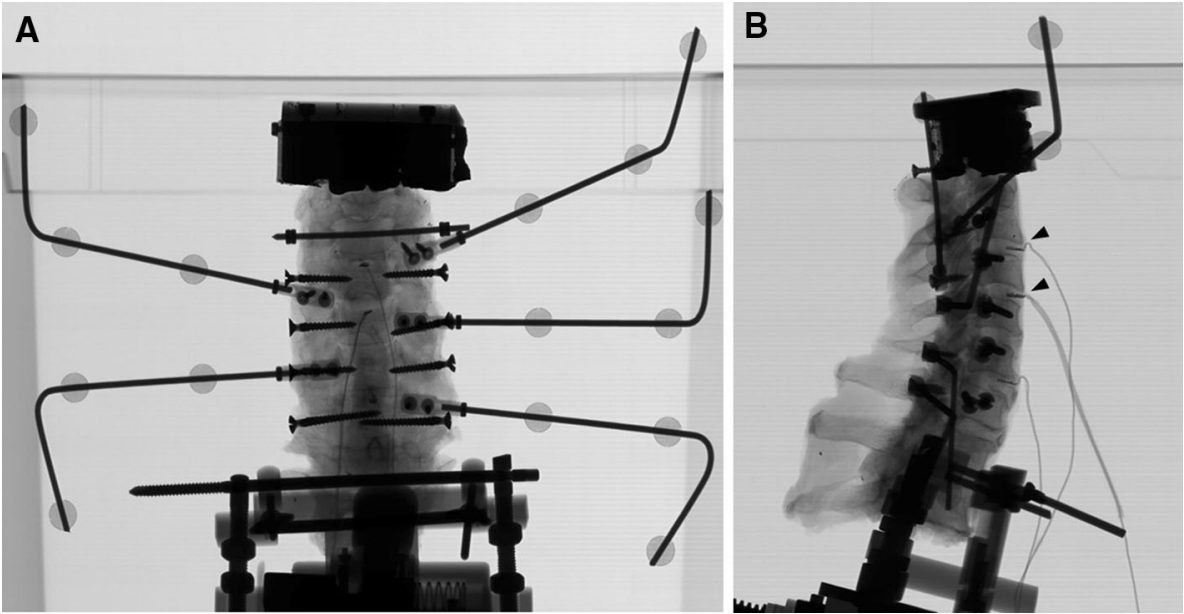

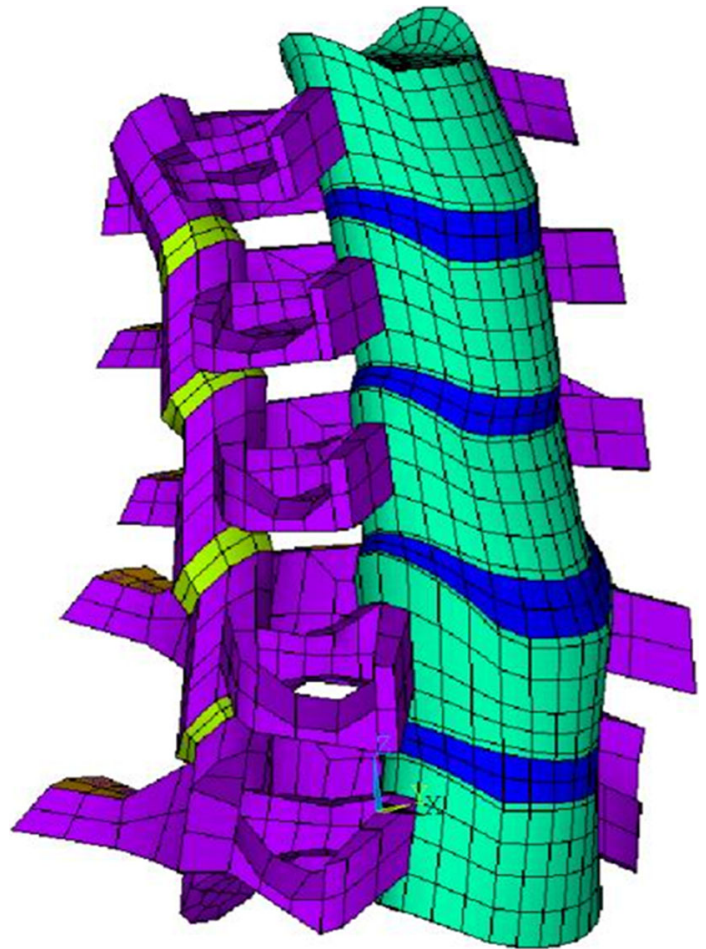

Fig. 3 Oblique view of the nonlinear three-dimensional FE model of the lower cervical spine composed by four functional spinal units from C3 to C7 [24]

been established for facets joints and between spinal processes. Finally, the C3-C7 FE model comprised a total of 5873 nodes, 4142 solid elements, 256 shell elements and 952 tension-only spring elements.

\section{Numerical simulation}

A follower load was simulated by using thermo-isotropic truss elements between each vertebra approximately located at the posterior third of the vertebral body close to the theoretical centre of rotation. By decreasing the temperature of these truss elements, shortening of their length was artificially obtained resulting in a compressive load applied perpendicularly to the disc space at each intervertebral segment.

The model was then tested in the same conditions for in vitro study by applying pure moments loading to the superior aspect of $\mathrm{C} 3$ in FE, LB and AR to a 2-Nm maximum moment loading with $0.2-\mathrm{Nm}$ steps. For each loading condition, the model was tested with $0-, 50-$ and $100-\mathrm{N}$ follower magnitude and with the follower placed $5 \mathrm{~mm}$ behind, $5 \mathrm{~mm}$ in front of and at the theoretical emplacement $(0 \mathrm{~mm})$.

Three-dimensional ranges of motion, intradiscal loads (anterior part of the nucleus) and facets forces were measured for each configuration.

\section{Results}

\section{Part 1 in vitro tests}

\section{Cervical spine curve}

The effect of the follower load on the spinal curve is presented in Fig. 4. Compared to intact spines, the mean change in $\mathrm{C} 3-\mathrm{C} 7$ sagittal angle was $5^{\circ} \pm 3^{\circ}(0.5-12)$ following the placement of the compressive load. The change was in flexion for $6 / 12$ specimens (that is reduction in lordosis) and in extension for $6 / 12$ specimens (that is increase in lordosis). The variation was $<5^{\circ}$ in $6 / 12$ cases and $<10^{\circ}$ in all cases but one (specimen R2: $11.9^{\circ}$ decreased).

\section{Ranges of motion}

Main motions in FE, $L B$ and $A R$ The six moments were grouped into three pairs: flexion/extension, left/right axial 
Fig. 4 Changes in cervical spine curve following the placement of the follower preload
Extension
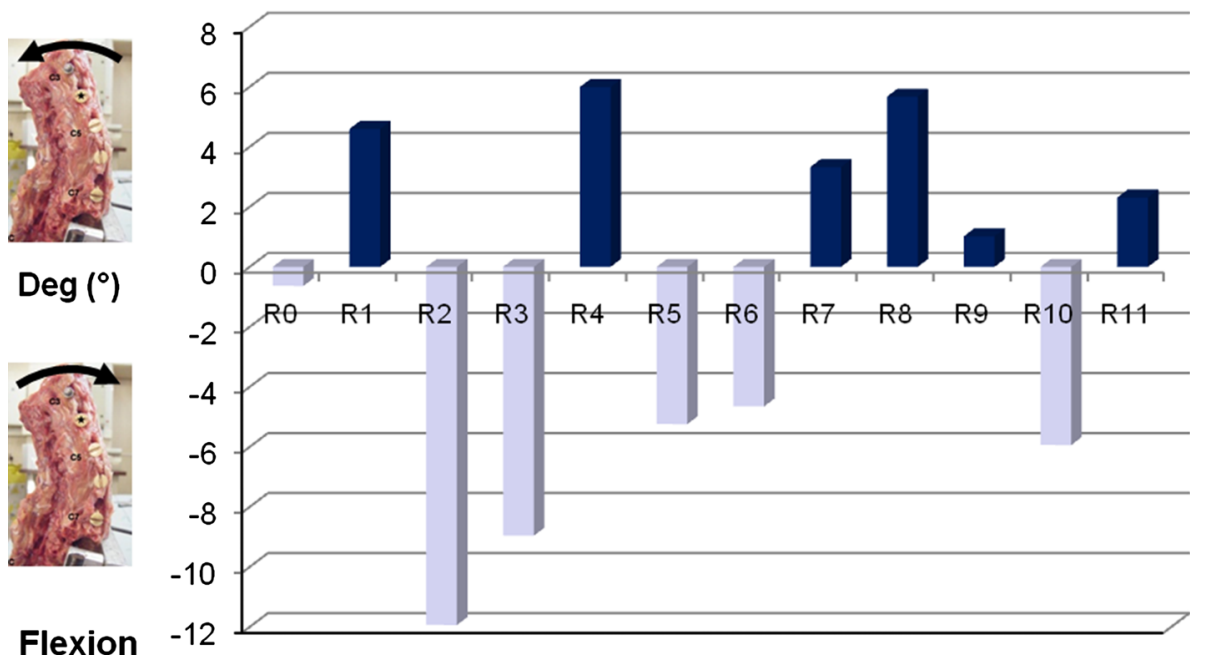

rotation and left/right lateral bending. Average load-displacement curves are illustrated in Fig. 5 for intact and loaded spines showing increase in hysteresis in axial rotation and lateral bending. Compared to intact spines, the mean C3-C7 ROM slightly increased from $54.6^{\circ} \pm 9^{\circ}$ (37-71) to $56.1^{\circ} \pm 9^{\circ}(38-72)$ in flexion-extension, $p=0.01 ;$ decreased from $45.4^{\circ} \pm 8^{\circ}(27-57)$ to $38.0^{\circ} \pm 7^{\circ}(21-48)$ in axial rotation, $p=0.002$; and decreased from $43.3^{\circ} \pm 6^{\circ}(32-51)$ to $37.3^{\circ} \pm 7^{\circ}(24-47)$ in lateral bending, $p=0.002$, Fig. $6 \mathrm{a}$.

Intersegmental angular ROMs $(\mathrm{C} 3 / \mathrm{C} 4, \mathrm{C} 4 / \mathrm{C} 5, \mathrm{C} 5 / \mathrm{C} 6$ and $\mathrm{C} 6 / \mathrm{C} 7)$ are summarised in Table 1 for intact and loaded spines.

Coupled motions in $A R$ and $L B$ Following the application of the follower load, the mean coupled axial rotation during lateral bending reduced from $24.6^{\circ} \pm 13^{\circ}(4-54)$ to $20.7^{\circ} \pm 11^{\circ}(3-45)$. It represented $54.7 \pm 26 \%(12-105)$ and $53 \pm 22 \%$ (14-95) of the main motion, respectively, without significant difference, Fig. $6 \mathrm{~b}$.

The mean coupled lateral bending during axial rotation reduced from $33.5^{\circ} \pm 6^{\circ}$ (26-43) to $24.6^{\circ} \pm 5.9^{\circ}(15-34)$, which represented $75.5 \pm 15.9 \% \quad(51-105)$ and $65.7 \pm 14.3 \%(37-85)$ of the main motion, respectively, $p<0.005$, Fig. 6 b.

\section{Intradiscal pressure}

Load-pressure curves were obtained for intact and loaded spines in flexion-extension, axial rotation and lateral bending (Fig. 7). At $\mathrm{C} 3-\mathrm{C} 4$ and $\mathrm{C} 4-\mathrm{C} 5$, intradiscal pressures were systematically higher for loaded spines than for intact spines for the three loading conditions. In contrast to

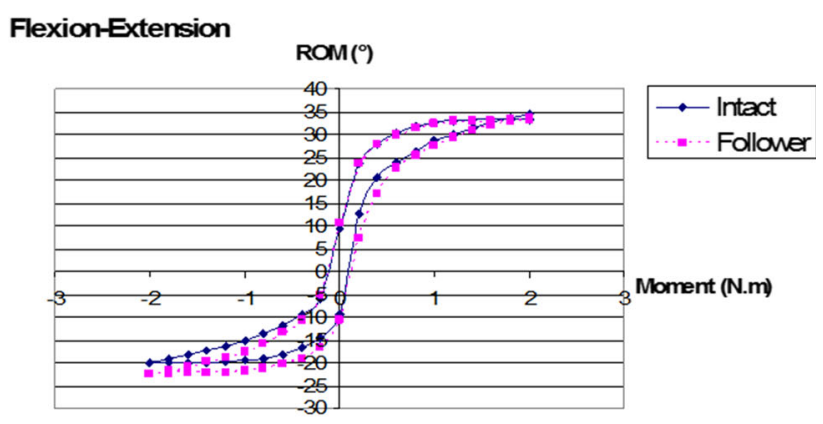

Axial Rotation
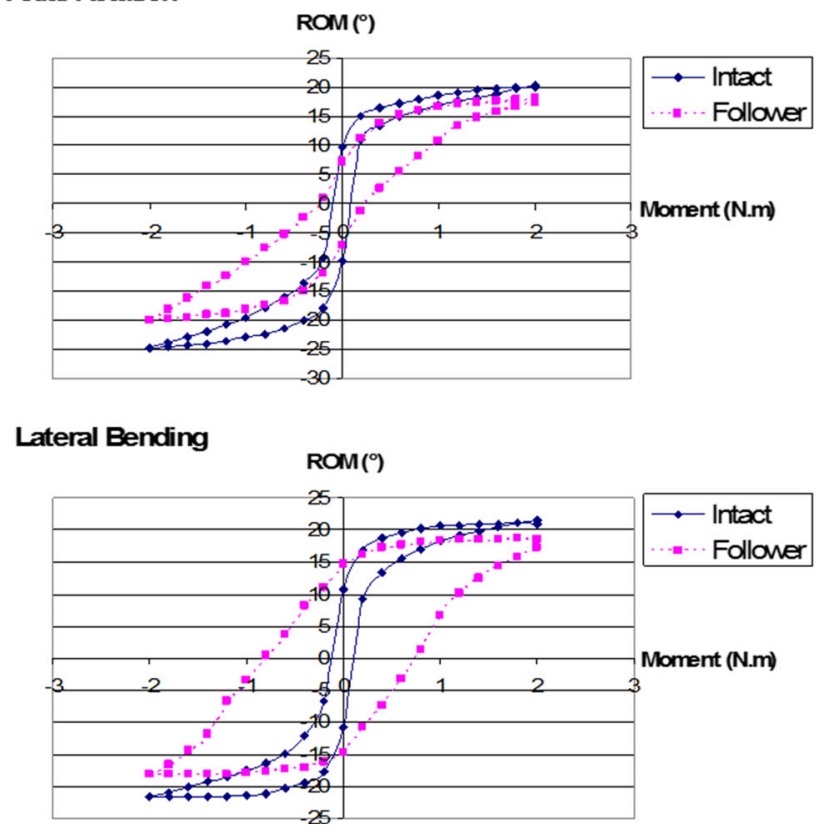

Fig. 5 Average load-displacement curves ( $n=12$ spines) in flexion-extension, axial rotation and lateral bending for intact and loaded spines 
A ROM in FE, ARand $L B$ for intact \& loaded spines

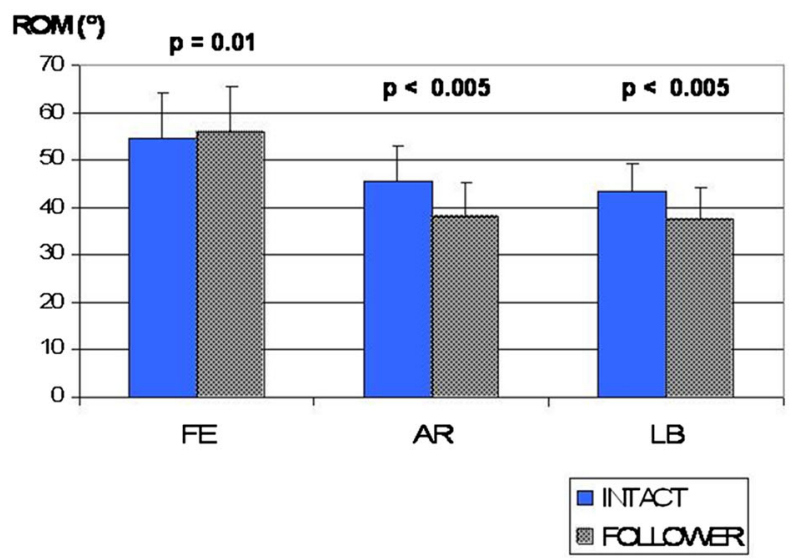

\section{B Coupled motion during AR and $L B$ for intact \&} loaded spines

coupled I

main motion (\%)

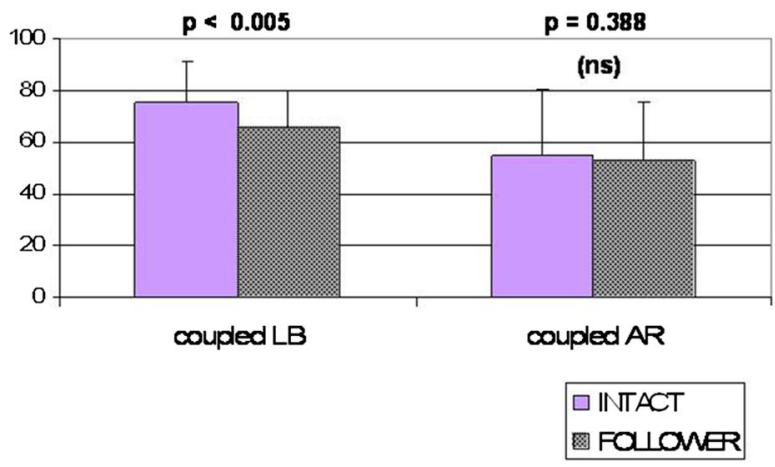

Fig. 6 ROM in FE, AR and LB for intact and loaded spines (a) and coupled motions during AR and LB for intact and loaded spines (b)

Table 1 Intersegmental ROMs for intact and loaded spines $(n=12)$ in the three loading conditions

\begin{tabular}{|c|c|c|c|c|}
\hline & $\mathrm{C} 3-\mathrm{C} 4$ & $\mathrm{C} 4-\mathrm{C} 5$ & $\mathrm{C} 5-\mathrm{C} 6$ & $\mathrm{C} 6-\mathrm{C} 7$ \\
\hline \multicolumn{5}{|c|}{ Flexion-extension } \\
\hline Intact & $12.7 \pm 3.6$ & $14.4 \pm 3.7$ & $13.9 \pm 4.1$ & $13.6 \pm 3.2$ \\
\hline Follower & $\begin{array}{l}12.9 \pm 3.5 \\
\text { ns }\end{array}$ & $\begin{array}{l}14.8 \pm 3.5 \\
p<0.05\end{array}$ & $\begin{array}{l}14.5 \pm 4.1 \\
p<0.01\end{array}$ & $\begin{array}{l}14 \pm 3.1 \\
p<0.01\end{array}$ \\
\hline \multicolumn{5}{|c|}{ Axial rotation } \\
\hline Intact & $15.7 \pm 3.8$ & $12.5 \pm 2.8$ & $9.1 \pm 2.8$ & $7.8 \pm 1.9$ \\
\hline Follower & $\begin{array}{l}12.8 \pm 3.2 \\
p<0.005\end{array}$ & $\begin{array}{l}11.9 \pm 3.1 \\
\mathrm{~ns}\end{array}$ & $\begin{array}{l}7.9 \pm 2.5 \\
p<0.01\end{array}$ & $\begin{array}{l}6.7 \pm 2.6 \\
p<0.05\end{array}$ \\
\hline \multicolumn{5}{|c|}{ Lateral bending } \\
\hline Intact & $11 \pm 2.3$ & $10.2 \pm 2.3$ & $10.2 \pm 3.4$ & $9.1 \pm 2.1$ \\
\hline Follower & $\begin{array}{l}9.5 \pm 2.7 \\
p<0.005\end{array}$ & $\begin{array}{l}9.1 \pm 2.6 \\
p<0.01\end{array}$ & $\begin{array}{l}8.7 \pm 3.4 \\
p<0.005\end{array}$ & $\begin{array}{l}7.5 \pm 2.3 \\
p<0.005\end{array}$ \\
\hline
\end{tabular}

flexion-extension, the shape of the load-pressure curves was significantly affected by the application of the follower load in axial rotation and lateral bending. Typical $V$-shape was replaced by a flat curve.

In flexion, the maximal IDP at $2 \mathrm{Nm}$ slightly increased from $7.35 \pm 2.8$ bar $(2.6-11)$ to $8.68 \pm 3.5$ bar $(2.8-13.8)$ for $\mathrm{C} 3-\mathrm{C} 4(+18.1 \%), p=0.016$, and from $7.58 \pm 3.8$ bar $(2.3-12)$ to $8.11 \pm 4$ bar $(3.5-13.9)$ for C4-C5 (+7 \%), without significant difference $(p=0.182)$.

\section{Part 2 finite element modelling}

\section{FE model validation}

Validation of the FEM was performed by comparing loaddisplacement curves of intact condition ( $0-\mathrm{N}$ follower load) provided by the model in flexion-extension, axial rotation and lateral bending with the corresponding curves from the in vitro experiments. The FEM was considered validated whether the load-displacement curve from the model was located inside the corridor observed from the in vitro study (Fig. 8).

\section{Effects of follower load}

Mean changes in ROM observed following the simulation of a 50-N compressive load are presented in Fig. 9 for the three loading conditions. ROM increased from $61^{\circ}$ to $62^{\circ}$ in $\mathrm{FE}$, and decreased from $31.5^{\circ}$ to $30.5^{\circ}$ in $\mathrm{AR}$ and from $31^{\circ}$ to $30.5^{\circ}$ in LB. Compared to intact condition, no more than $10 \%$ variation was observed with regard to the different magnitude and positioning simulated. Maximal variation of ROM in FE was observed with $100-\mathrm{N}$ follower preload $(+3.5 \%)$, and the greatest difference between intact and loaded condition was observed for $50 \mathrm{~N}$ at $-5 \mathrm{~mm}$ in $\mathrm{AR}$ (ROM decreased from $31.4^{\circ}$ to $28.3^{\circ}$, that is $-9.9 \%)$.

Concerning intradiscal loads, aspect of load-pressure curves is presented in Fig. 10 for intact and 50-N loaded spines. Compared to intact spines, intradiscal loads were systematically increased following simulation of compressive load. In flexion, at $2 \mathrm{Nm}$, IDP increased by approximately 22 and $26 \%$ at $\mathrm{C} 3-\mathrm{C} 4$ and $\mathrm{C} 4-\mathrm{C} 5$, respectively.

Finally, facets forces were systematically increased by applying compressive preload by approximately $5-10 \%$ at $2 \mathrm{Nm}$ in extension, 7-12\% in axial rotation and 7-9\% in lateral bending, Fig. 11. 
Fig. 7 Average intradiscal pressures at $\mathrm{C} 3-\mathrm{C} 4$ and $\mathrm{C} 4-\mathrm{C} 5$ $(n=12$ spines) in flexionextension, axial rotation and lateral bending

\section{C3-C4}

IDP in Flexion-Extension for C3-C4

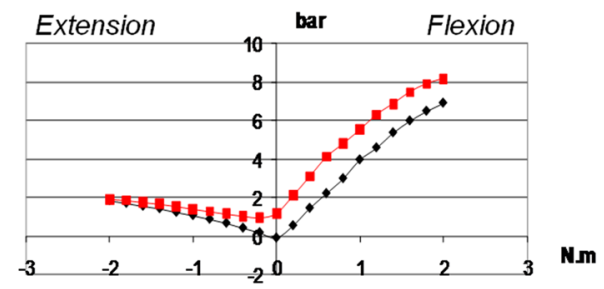

IDP in Axial Rotation for C3-C4

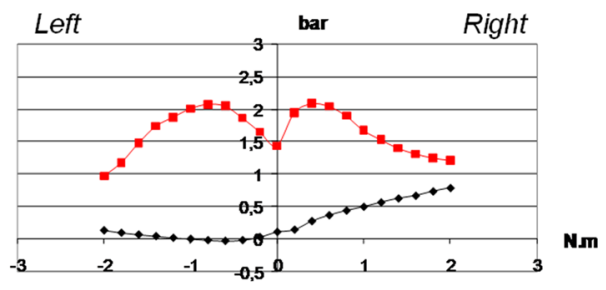

IDP in LateralBending for C3-C4

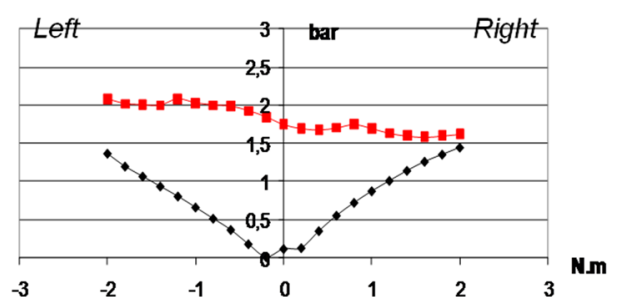

C4-C5

IDP in Flexion-Extension forC4-C5

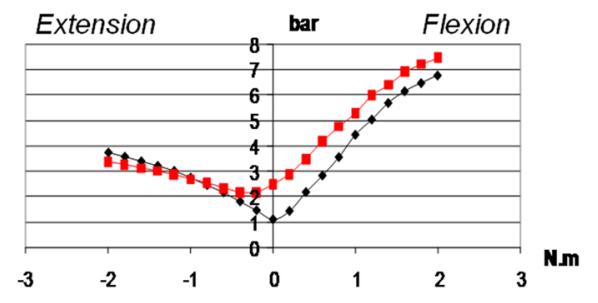

IDP in Axial Rotation for C4-C5

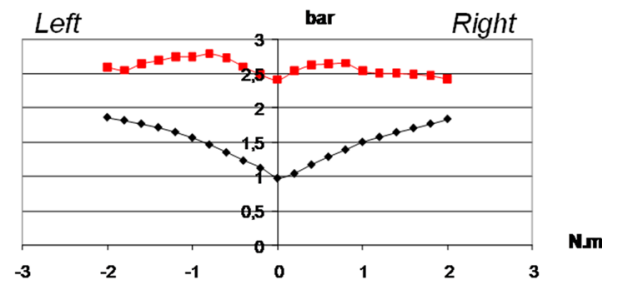

IDP in Lateral Bending for C4-C5

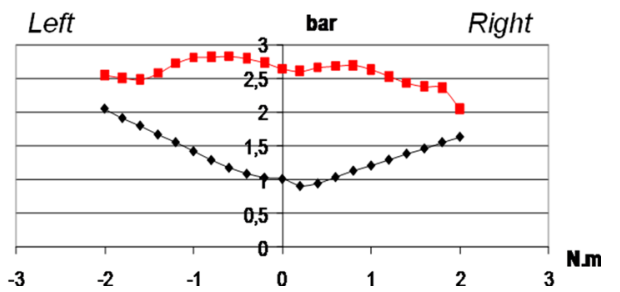

\section{Discussion}

The objective of this study was to evaluate the influence of applying a follower preload on the biomechanical behaviour of the cervical spine using both in vitro human cadaveric and numerical simulating methods.

\section{In vitro protocol}

Our protocol allowed for measurement of 3D angular and linear displacement for each load case and determination of main and coupled motions. The use of the $\mathrm{EOS}^{\mathrm{TM}}$ stereographic system gave us the opportunity to precisely determine the relative position of markers-dependent frame with reference to the anatomical frame of each vertebra. The values of the intact model in our study were comparable to those previously reported in the literature, suggesting the reliability of our in vitro protocol [6, 27-29].

\section{Application of compressive follower preload}

Comparing the follower load to a simple vertical load, Patwardhan et al. [13] demonstrated that cervical spine segments could support a compressive load of $250 \mathrm{~N}$ without instability whereas pure vertical compressive load resulted in great changes in lordosis angle at only 20- to 40-N loading. Putting each spinal segment in nearly pure compression, a follower load increased the load-carrying capacity of the spine specimens. Thus, we did not investigate a simple vertical load to simulate the physiological compressive muscles action during experimental tests.

The follower load consists of a compressive load applied along the spine, perpendicular to the transversal plane of the disc space and tangent to the spinal curve, in order to put the spine in compression with minimal changes in spinal curvature $[12,30]$. The position of guiding screws by which the follower load is applied may affect the type of sagittal bending moment induced and thus the effect of 


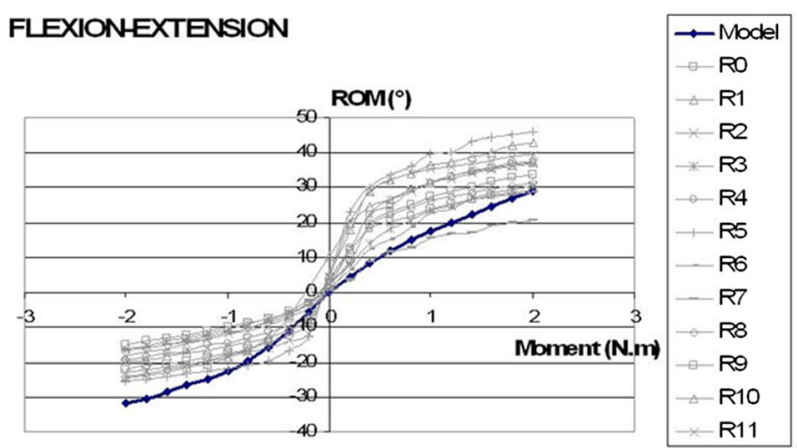

\section{AXIALROTATION}

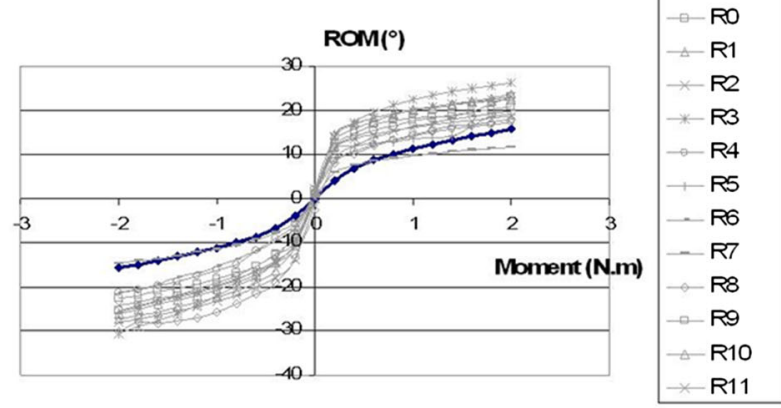

\section{LATERAL BENDING}

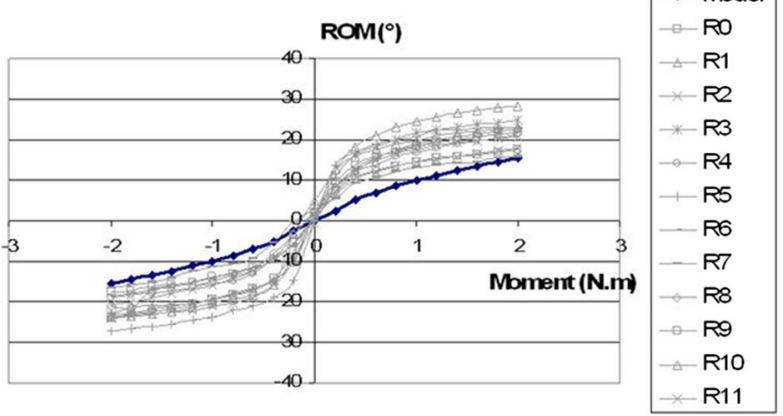

Fig. 8 Load-displacement curves provided by the model were compared to those measured from experimental tests for the 12 specimen in FE, AR and $\mathrm{LB}$

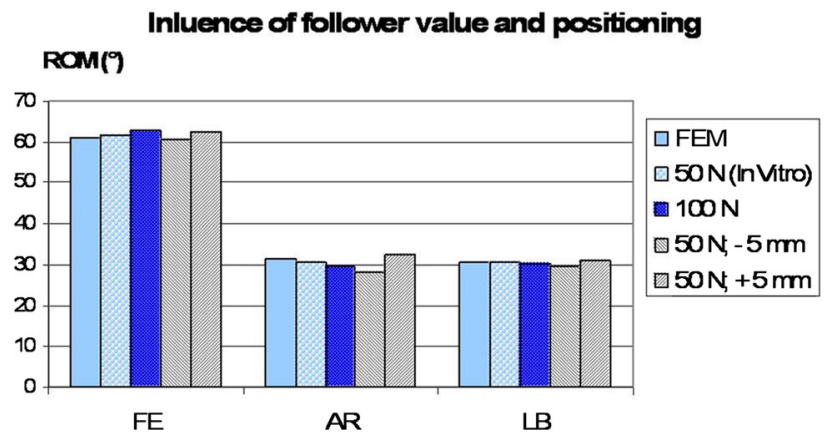

Fig. 9 ROM in FE, AR and LB corresponding to intact condition, simulation of a 50- and 100-N compressive load and simulation of $\pm 5 \mathrm{~mm}$ offset regarding theoretical emplacement of the follower load follower load on spinal curve. With regard to the balance point, posterior position may result in extension moment and induce increase in cervical spine lordosis whereas anterior positioning may result in a more flexed spine, affecting potentially the biomechanical behaviour of the spinal segment. Our study demonstrated that positioning the follower load between anterior and posterior ridges of the transverse process resulted in only minor changes in spinal curve (only $5^{\circ}$ on average), suggesting that this anatomical landmark was close to the natural centre of rotation and was a reliable landmark in terms of reproducibility.

\section{Influence on kinematics, intradiscal pressures and facet loads}

Under a follower load, we found that the biomechanical behaviour of cervical spine specimens was significantly more affected in axial rotation and lateral bending than in flexion-extension.

\section{Flexion-extension}

In flexion-extension, variations in terms of total ROM, NZ and profile of load-displacement curves were negligible. Only significant effects observed were increase in intradiscal pressures (around $10 \%$ ) slightly inferior to the results suggested by the model. Considering that, by applying follower load, the objective was to put each intervertebral segment in compression, close to in vivo conditions, without affecting the native biomechanical behaviour of spines, our study suggests that this method is quite adequate for flexion-extension.

In addition, regarding the results from our numerical simulation study concerning the impact of follower positioning, we observed that the follower could be placed in an area of $10 \mathrm{~mm}$ around the theoretical CMR without major changes in spine kinematics.

\section{Axial rotation and lateral bending}

In our study, not only the extent of main motion was significantly reduced in axial rotation and lateral bending but also coupled motion was affected following application of follower load. Shape of load-displacement curves was characterised by a significant increase in the hysteresis with significant changes in the magnitude of NZ, suggesting that the quality of motion could also be affected. These findings have already been reported in the lumbar spine through human experimental study [15] and through a porcine model [9]. In addition, significant alterations were observed for load-pressure curves in axial rotation and lateral 

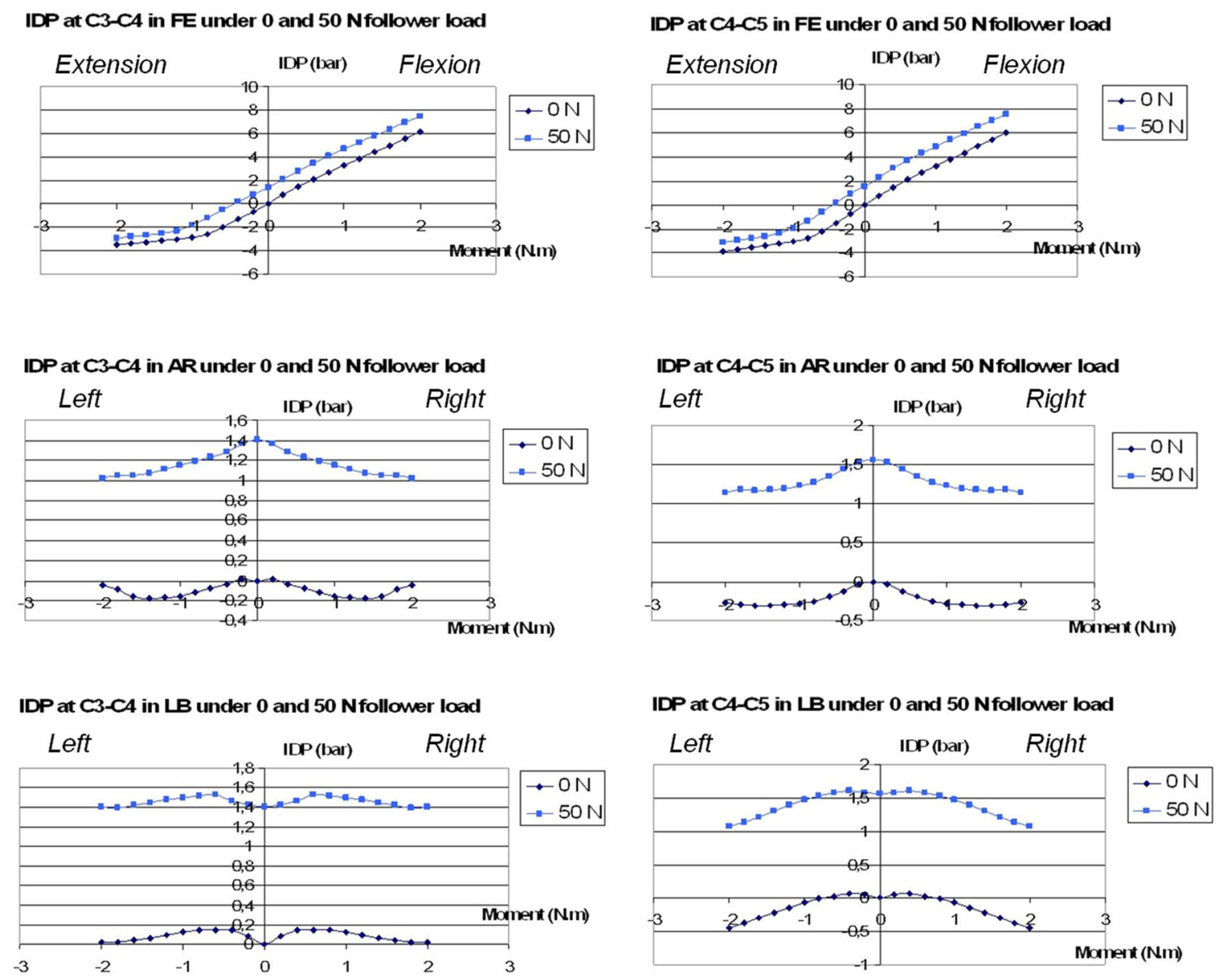

Fig. 10 Load-pressure curves provided by the FE model for intact and 50-N loaded condition in FE, AR and LB

bending, suggesting that application of follower load induces a less physiological load transfer trough the disc space, potentially due to shear forces mentioned above. Similar changes in profile of load-pressure curves after simulation of muscles forces have also been reported by Pospiech et al. [31]. Considering that these findings were not confirmed through our numerical simulation, we hypothesised that these changes in spinal kinematics may be the consequence of the set-up used in vitro to apply the compressive preload.

In fact, nearly pure compression of spinal segment is probably obtained during FE whereas during AR and LB, the application of follower load may result in a combination of compression and shear forces inducing significant changes in spine kinematics. The presence of sliding frictions along the follower load path during axial rotation and lateral bending is highly suggested by the increase in hysterisis on load-displacement curves. As described by Patwardhan et al. [14], these frictions may induce at each contact between screw heads and flexible cables a double-component force consisting of a tangential one perpendicular to the transversal plane of the disc space (compressive force) and a transversal one parallel to the disc space (shear force).
However, it is difficult to determine precisely the relative value of these two forces during in vitro tests. By waxing flexing cables and smoothly drilling the screw heads, the frictions can only be limited considering that contact between screws and flexible cables is unavoidable.

These results are concordant with those mentioned by Miura and Cripton [18] which reported that the application of preload resulted in reduction in spinal motion differentially depending on loading condition. The authors consequently proposed to apply different moments in different directions. Comparing two different protocols, they found that pure moments of $2 \mathrm{Nm}$ in FE and LB and $4 \mathrm{Nm}$ in AR (2:4:2 protocol) reproduced more closely in vivo values than equal moments of $1 \mathrm{Nm}$ in each direction.

Finally, coupled motions in the lower cervical spine have been reported to be secondary to the orientation of facets joints [25, 32]. By compressing the facet joints as demonstrated through our numerical simulation investigation (approximately $10 \%$ increase in facets forces), the follower load could affect more specifically coupled motions during axial rotation and lateral bending than flexionextension, which is a relatively pure motion in the sagittal plane. 


\section{Facet loads at $2 \mathrm{NmExtension} \mathrm{under} \mathrm{O}$ and $50 \mathrm{~N}$ preload}
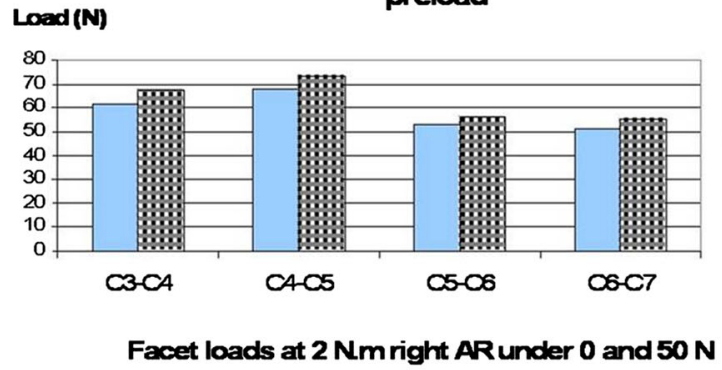
preload

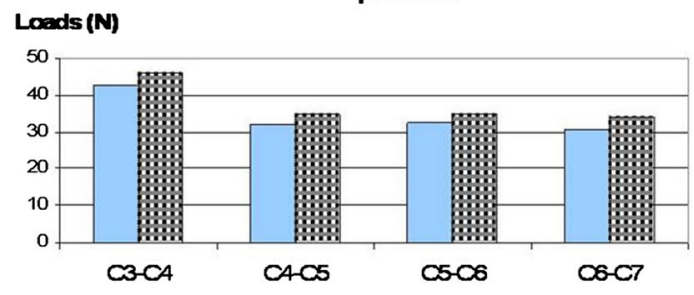

Facet loads at $2 \mathrm{Nm}$ right LB under 0 and $50 \mathrm{~N}$ preload

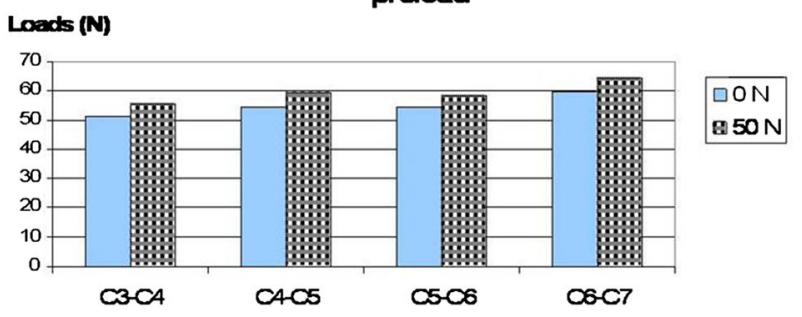

Fig. 11 Facets forces in extension, right AR and right LB

\section{Relevance of follower load for in vitro tests}

Theoretically, the follower load represents an attractive option permitting to simulate more closely in vivo conditions by reproducing head weight and cervical muscles action. However, our results suggested that the placement of such compressive preload may significantly affect the biomechanical behaviour of spine specimen especially during $\mathrm{AR}$ and $\mathrm{LB}$ and thus leads to some degree of variability from a specimen to an other.

Considering our results and that follower load is relatively time-consuming and technically demanding, we assume that the application of follower load should be considered according to the goal of experimentation and especially the type of instrumentation tested. When intend to investigate classical rigid spinal implants and rigid constructs, follower load may not be beneficial during in vitro tests.

On the contrary, when there is a risk of separation between implant and bone surfaces or between implant parts, as observed for disc prostheses or cages alone [16, 33, 34], segmental compressive force should be useful, thus limiting the separation of bearing surfaces or separation between implant and endplates, and the use of a follower load is therefore recommended. Nevertheless, we suggest applying follower load only in flexion-extension seeing the results mentioned in the present study.

Conflict of interest None.

\section{References}

1. Barrey C, Mosnier T, Jund J, Perrin G, Skalli W (2009) In vitro evaluation of a ball-and-socket cervical disc prosthesis with cranial geometric center. J Neurosurg Spine 11:538-546

2. Goel VK, Panjabi MM, Patwardhan AG, Dooris AP, Serhan H (2006) Test protocols for evaluation of spinal implants. J Bone Joint Surg 88-A:103-109

3. MacAfee PC, Cunningham B, Dmitriev A, Hu N, Woo Kim S, Cappuccino A, Pimenta L (2003) Cervical disc replacementporous coated motion prosthesis: a comparative biomechanical analysis showing the key role of the posterior longitudinal ligament. Spine 28:S176-S185

4. Puttlitz CM, Rousseau MA, Xu Z, Hu S, Tay BK, Lotz JC (2004) Intervertebral disc replacement maintains cervical spine kinematics. Spine 29:2809-2814

5. Panjabi MM, Crisco JJ, Vasavada A, Oda T, Cholewicki J, Nibu $\mathrm{K}$ et al (2001) Mechanical properties of the human cervical spine as shown by three-dimensional load-displacement curves. Spine 26:2692-2700

6. Wen N, Lavaste F, Santin JJ, Lassau JP (1993) Three-dimensional biomechanical properties of the human cervical spine in vitro. I. Analysis of normal motion. Eur Spine J 2:2-11

7. Wilke H-J, Wenger K, Claes L (1998) Testing criteria for spinal implants: recommendations for the standardization of in vitro stability testing of spinal implants. Eur Spine J 7:148-154

8. Goel VK, Wilder DJ, Pope MH, Edwards WT (1995) Controversy: biomechanical testing of the spine. Load-controlled versus displacement-controlled analysis. Spine 20:2354-2357

9. Gardner-Morse MG, Stokes IA (2003) Physiological axial compressive preloads increase motion segment stiffness, linearity and hysteresis in all six degrees of freedom for small deplacements about the neutral posture. J Orthop Res 21:547-552

10. Panjabi MM, Krag M, White AA, Southwick WO (1977) Effects of preload on load displacements curves of the lumbar spine. Orthop Clin N Am 8:181-192

11. Panjabi MM, Cholewicki J, Nibu K et al (1998) Criticial load of the human cervical spine: an in vitro experimental study. Clin Biomech 13:11-17

12. Patwardhan AG, Havey RM, Meade KP, Lee B, Dunlap B (1999) A follower load increases the load-carrying capacity of the lumbar spine in compression. Spine 24:1003-1009

13. Patwardhan AG, Havey RM, Ghanayem AJ, Diener H, Meade KP, Dunlap B, Hodges SD (2000) Load-carrying capacity of the human cervical spine in compression is increased under a follower load. Spine 25:1548-1554

14. Patwardhan AG, Havey RM, Carandang G, Simonds J, Voronov LI, Ghanayem AJ, Meade KP, Gavin TM, Paxinos O (2003) Effect of compressive follower preload on the flexion-extension response of the human lumbar spine. J Orthop Res 21:540-546

15. Rohlmann A, Neller S, Claes L, Bergmann G, Wilke HJ (2001) Influence of a follower load on intradiscal pressure and intersegmental rotation of the lumbar spine. Spine 26:E557-E561

16. Patwardhan AG, Carandang G, Ghanayem AJ, Havey RM, Cunningham B, Voronov LI, Philips FM (2003) Compressive 
preload improves the stability of anterior lumbar interbody fusion cage constructs. J Bone Joint Surg 85-A:1749-1756

17. Renner SM, Natarajan RN, Patwardhan AG, Havey RM, Voronov LI, Guo BY, Andersson GB, An HS (2007) Novel model to analyze the effect of a large compressive follower preload on range of motions in a lumbar spine. J Biomech 40:1326-1332

18. Miura T, Panjabi MM, Cripton PA (2002) A method to simulate in vivo cervical spine kinematics using in vitro compressive preload. Spine 27:43-48

19. Amevo B, Worth D, Bogduk N (1991) Instantaneous axes of rotation of the typical cervical motion segments: a study in normal volunteers. Clin Biomech 6:111-117

20. Dvorak J, Panjabi M, Novotny J, Antinnes J (1991) In vivo flexion/extension of the normal cervical spine. J Orthop Res 9:828-834

21. Van Mameren H, Sanches H, Beursgens J, Drukker J (1992) Cervical spine motion in the sagittal plane II. Position of segmental averaged instantaneous centers of rotation-a cineradiographic study. Spine 17:467-474

22. Dubousset J, Charpak G, Dorion I, Skalli W, Lavaste F, Deguise J et al (2005) A new 2D and 3D imaging approach to musculoskeletal physiology and pathology with low-dose radiation and the standing position: the EOS system. Bull Acad Natl Méd 189:287-297

23. Rousseau MA, Laporte S, Chavary-Bernier E, Lazennec JY, Skalli W (2007) Reproducibility of measuring the shape and three-dimensional position of cervical vertebrae in upright position using the EOS stereoradiography system. Spine 32:2569-2572

24. Laville A, Laporte S, Skalli W (2009) Parametric and subjectspecific finite element modelling of the lower cervical spine. Influence of geometrical parameters on the motion patterns. J Biomech 42:1409-1415

25. Maurel N, Lavaste F, Skalli W (1997) A three-dimensional parameterized finite element model of the lower cervical spine.
Study of the influence of the posterior articular facets. J Biomech 9:921-931

26. Rousseau MA, Bonnet X, Skalli W (2008) Influence of the geometry of a ball-and-Socket intervertebral prosthesis at the cervical spine. A finite element study. Spine 33:E10-E14

27. Bogduk N, Mercer S (2000) Biomechanics of the cervical spine. I: normal kinematics. Clin Biomech 15:633-648

28. Watier B (1997) Etude expérimentale du rachis cervical: comportement mécanique in vitro et cinématique in vivo [thesis, in french]. Ecole Nationale Supérieure d'Arts et Métiers, Arts et Metiers ParisTech, Paris

29. White AA, Panjabi MM (1990) Clinical biomechanics of the spine, 2nd edn. Lippincott, Philadelphia

30. Rohlmann A, Zander T, Rao M, Bergmann G (2009) Applying a follower load deliver realistic results for simulating standing. J Biomech 42:1520-1526

31. Pospiech J, Stolke D, Wilke H, Claes L (1999) Intradiscal pressure recordings in the cervical spine. Neurosurgery 44:379-384

32. Veron S, Skalli W, Maurel N, Lavaste F (1995) Helicoidal axes to characterize cervical spine kinematics. A finite element study [in french]. French Society of Radiology and European Society of Biomechanics Congress, Toulouse

33. Kim SH, Chang UK, Chang JC, Chun KS, Lim TJ, Kim DH (2009) The changes in range of motion after a lumbar spinal arthroplasty with Charite ${ }^{\mathrm{TM}}$ in the human cadaveric spine under physiologic compressive follower preload: a comparative study between load control protocol and hybrid protocol. J Korean Neurosurg 46:144-151

34. Barrey C, Campana S, Persohn S, Perrin G, Skalli W (2012) Cervical disc prosthesis versus arthrodesis using one-level, hybrid and two-level constructs. An in vitro investigation. Eur Spine J 21(3):432-442 